Singh, S., \& Walia, N. (2020). Time-series and cross-sectional momentum in Indian stock market. Copernican Journal of Finance \& Accounting, 9(3), 161-176. http://dx.doi.org/10.12775/ CJFA.2020.018

\title{
TIME-SERIES AND CROSS-SECTIONAL MOMENTUM IN INDIAN STOCK MARKET
}

Keywords: cross-sectional momentum, time-series momentum, Indian stock market.

\section{J E L Classification: G11, G12.}

Abstract: Present study documents the significant time-series and cross-sectional momentum profits in Indian stock market. These profits remain significant even after adjusting market, size and value factors. Further time-series momentum effect remains significant when we hold securities for longer period signalling that time-series momentum do not reverse in the long run. When we compare the performances of time series and cross-sectional momentum payoffs, we find that time-series momentum strategies generate superior returns than cross-sectional momentum strategies and net long investments in time-series momentum strategies is the main source of difference between the performances of these two approaches.

Date of submission: June 9, 2020; date of acceptance: August 18, 2020.

* Contact information: jeetsimarkama193@gmail.com, University School of Applied Management, Punjabi University, Patiala, phone: +91 9646244332; ORCID ID: https://orcid.org/0000-0003-3497-2177.

** Contact information: nidhiwalia79@gmail.com, University School of Applied Management, Punjabi University, Patiala, phone: +91 9872022100; ORCID ID: https://orcid. org/0000-0002-3197-2326. 


\section{INTRODUCTION}

In recent years, Momentum investing based on buying and selling financial assets on the basis of their past returns has received substantial attention from the financial researchers. Majority of the research on momentum has concentrated on cross-sectional momentum. For instance, Jegadeesh and Titman (1993) have demonstrated that stocks that performed better than peers in the past will continue to perform better in their near future (next 3 to 12 months) and similarly stocks that have underperformed in the past will continue to underperform in the near future. This phenomenon of selecting the stocks based on their relative performances over some past period is termed as cross-sectional momentum. Research studies have proved the substantial existence of cross-sectional momentum (relative momentum) across different asset classes and financial markets (Jegadeesh \& Titman, 2001; Griffin, Ji \& Martin, 2003; Asness, Moskowitz \& Pedersen, 2013). Many research studies have proved the profitability of cross-sectional momentum strategies in the Indian market (Sehgal \& Jain, 2015; Garg \& Varshney, 2015; Maheshwari \& Dhankar, 2017). Recently Moskowitz, Ooi and Pedersen (2012) suggested an alternative framework for the selection of financial assets which is based on the absolute performance of financial assets over some past period. They termed this approach as "time-series momentum". Moskowitz et al. (2012), taking a sample of 58 liquid contracts proved that buying and selling financial assets on the basis of their own past performance performs better than traditional cross-sectional momentum.

Although most of the research studies on relative momentum concentrate on individual stocks, time-series momentum (absolute momentum) literature has taken into consideration a sample of commodities, currencies and indices. Very few studies have tested the profitability of time-series momentum strategies among individual stocks. The direct motivation for this study arises from the fact that most of the literature on momentum focuses on cross-sectional momentum. There are very few studies on time-series momentum that focuses only on developed markets. Nevertheless, in recent past, emerging markets have offered tremendous opportunities for growth for investors. Therefore, it is vital to examine the performance of time-series momentum strategies in emerging markets. Our study addresses this gap by examining the performances of the time series and cross-sectional momentum strategies in the Indian eq- 
uity market. We also investigate potential sources of difference between the performance of these two strategies. Indian stock market is the second most attracting emerging stock market. It has attracted record foreign inflow in recent past ${ }^{1}$. In our knowledge, this is the first study that examines the performance of time-series momentum strategies in the Indian market.

In the present study, we first examine the performance of cross-sectional and time-series momentum strategies and find that both kinds of strategies generate significant profits. These profits remain significant even after adjusting market and Fama-French factors. Absolute momentum strategies generate superior returns than relative momentum strategies. Absolute momentum profits remain significant even when we hold portfolios for longer period signalling that absolute momentum profits do not reverse in long period. In contrast, relative momentum profits do not remain significant in longer period. After examining the performances of both kind of momentum strategies, we regress relative momentum returns against absolute momentum return and other way around. We notice that regressing cross-sectional momentum returns against time-series momentum return results in negative alphas whereas regressing time-series momentum returns against cross-sectional momentum returns results in significant positive alphas. Finally, we notice that cross-sectional momentum strategies are "zero-investment" strategies ${ }^{2}$ (equal stocks in winner and loser portfolios) whereas in time-series momentum strategies stocks in winner and loser portfolios fluctuate with market states. We find that net long investment in time-series momentum strategies is the main reason for the superiority of absolute momentum strategies over relative momentum strategies.

The study tries to fill the gap in existing momentum literature by examining the performance of time-series momentum strategies in the world's second-biggest emerging market India. The study provides significant evidence of time-series momentum effect in the Indian market, which cannot be captured by traditional asset pricing models. Our study also contributes to the existing literature by finding the source of difference between the performances of

${ }^{1}$ Bloomberg survey of global investors and traders (2019) revealed that India is the second most preferred emerging equity market among the global fund managers.

2 Zero investment strategies or zero net investment strategies are investment strategies where the net value of the portfolio is zero. This is done by forming equal long and short portfolios. 
cross-sectional and time-series momentum strategies. The study also provides fresh evidence of cross-sectional momentum in the Indian market. We have organized the rest of the paper as follows. Section 2 gives a summary of the existing literature on momentum investing. Section 3 describes data and research methodology. Findings and discussions of the study are reported in section 4 and 5 , respectively. Section 6 concludes the research study.

\section{LITERATURE REVIEW}

In finance, momentum means price continuation patterns. Jegadeesh and Titman (1993) initially tested the performance of relative momentum strategies in the US market. They reported that relative momentum strategies generate large and significant returns. After their work, Chan, Jegadeesh and Lakonishok (1996) and Conrad and Kaul (1998) also confirmed the presence of momentum effect in the US market. Rouwenhorst (1998) examined the momentum effect in Europe. By taking into consideration the 12 European markets, the study documented significant momentum effect in Europe. Griffin et al. (2003) explored the performance of cross-sectional momentum strategies across 40 developed and emerging markets and found significant momentum effect in 32 financial markets. Further, academic studies have reported significant cross-sectional momentum effect across multiple asset classes such as commodities, corporate bonds, currencies, mutual funds, real estate (Okunev \& White, 2003; Derwall, Huij, Brounen \& Marquering, 2009; Beracha \& Skiba, 2011; Jostova, Nikolova, Philipov \& Stahel, 2013; Fuertes, Miffre \& Fernandez-Perez, 2015; Grobys \& Sapkota, 2019). Research studies have also proved the efficacy of relative momentum strategies in the Indian stock market. Sehgal and Balakrishnan (2002) initially observed significant cross-sectional momentum effect in the Indian market. Further, several academic studies confirm these findings (Garg \& Varshney, 2015; Maheshwari \& Dhankar, 2017; Mohapatra \& Misra, 2020).

Although there is a vast literature on cross-section momentum, the literature on time-series momentum is limited. Moskowitz et al. (2012) initially proved the superiority of time-series momentum strategies over cross-sectional momentum strategies. Further, Menkhoff, Sarno, Schmeling and Schrimpf (2012) confirmed these findings in currency markets. Bird, Gao and Yeung (2017) extended the work of Moskowitz et al. (2012) and tested the performances of absolute and relative momentum strategies across 24 developed fi- 
nancial markets. They confirmed the superiority of time-series momentum strategies over cross-sectional momentum strategies. Goyal and Jegadeesh (2018) went one step further, and they try to find out the major source of differences between the performances of time series and cross-sectional momentum strategies. They reported that absolute momentum strategies perform better than relative momentum strategies and "time-varying net long position" is the main source behind this superiority. Lim, Wang and Yao (2018) proved that absolute momentum effect is pervasive as they proved the efficacy of time-series momentum strategies across multiple geographical markets and sub-periods.

\section{DATA AND RESEARCH METHODOLOGY}

For the selection of the sample, authors initially consider the month-end adjusted closing prices of all the companies listed on BSE (Bombay Stock Exchange) from January 2002 to October 2019. The span of the sample period covers both the bull and bear phases of the Indian stock market. After the initial selection, we further screened the sample and selected only those companies that have complete monthly stock price data for the above-mentioned sample period. Following Du (2008), the study also dropped the penny stocks from the sample to avoid any potential biases. Finally, we selected 458 stocks for analysis. We have collected the required data for the study from the multiple sources. The monthly adjusted stock prices were extracted from CMIE Prowess financial database $^{3}$. We have used 91- day Treasury Bill (T-Bill) yield as a proxy for the risk-free return. We collected the T-Bill returns from the RBI's website. Data regarding Fama-French factors ${ }^{4}$ were obtained from the Data library for Indian market maintained by IIM Ahmedabad. To remove the effect of the outliers from the data, we winsorize the data at $0.5 \%$ level both at lower and high ends as suggested by Bali, Engle and Murray (2016). From the adjusted stock prices, we calculated the logarithmic stock returns using the following formula.

3 Prowess is the "largest database of the financial performance of Indian companies" maintained by centre for monitoring Indian economy private limited.

${ }^{4}$ Fama and Frech (1992) introduced the three-factor asset pricing model to explain cross-sectional variation in financial assets returns. These three factors are size (SMB), value (HML) and market factor. 


$$
\mathrm{r}_{\text {it }}=\ln \left(\mathrm{P}_{\mathrm{it}} / \mathrm{P}_{\mathrm{it}-1}\right)
$$

where $r_{i t}$ represents log return of a stock at time $t, P_{i t}$ represents price of that stock at time $t$ and $\mathrm{P}_{\mathrm{it}-1}$ represents the price of the stock on $\mathrm{t}-1$ month, and $\ln$ is the natural logarithm.

\section{Formulation of momentum strategies}

To formulate the cross-sectional strategies, we follow the methodology as suggested by Jegadeesh and Titman (1993) and Lin (2019). We sort the stocks into deciles on the basis of their prior 11 month returns from the month t-12 to month $\mathrm{t}-2$. Top deciles (best 10\%) represents the winner portfolio, and bottom decile (worst 10\%) represent loser portfolio. For portfolio construction equal weights, we give equal weight to each stock in winner and loser portfolio. We long (buy) the stocks in winner portfolio and short (sell) the stocks in loser portfolio. After this, we hold these stocks for five different periods $(1,3,6,9,12$ months). To prevent bid-ask bias and lagged reaction, the study introduces a one-month gap between formulation and holding period (Jegadeesh \& Titman, 2001). For portfolio rebalancing, the present study uses buy and hold strategy. Finally, we calculate the cross-sectional momentum as the difference between winner and loser portfolio's returns.

Moskowitz et al. (2012) suggested the methodology for the construction of time-series momentum strategies. Firstly, for every stock we calculate prior 11 months returns from the month $\mathrm{t}-12$ through month $\mathrm{t}-2$. After calculating returns for every stock, we sort the stocks into two portfolios. The stocks that generated positive returns are categorized as winners and stocks that generated negative returns are categorized as losers. To make time-series momentum returns directly comparable with cross-sectional momentum returns, we invest in $20 \%$ of total stocks. For the portfolio rebalance and micro-structure biases, we adopted the same methodology as mentioned in the above paragraph.

\section{Risk-adjusted momentum returns}

For calculation of risk-adjusted momentum returns, authors first compute excess cross-sectional and time-series momentum returns by subtracting risk- 
free return from cross-sectional and time-series momentum returns. Then we estimate alphas of both cross-sectional strategies and time-series momentum strategies by regressing excess cross-sectional and time-series momentum returns on CAPM and Fama-French risk factors. We used the following equations to calculate excess returns, CAPM alpha and Fama-French alpha.

$$
\mathrm{R}_{\mathrm{et}}=\mathrm{R}_{\mathrm{mt}}-\mathrm{R}_{\mathrm{ft}}
$$

where $R_{e t}$ represents excess return at time $t, R_{m t}$ represents market return at time $t$ and $R_{f t}$ risk-free return at time.

$$
\alpha_{C A P M}=R_{e}-\beta\left(R_{m r}-R_{f}\right)
$$

where $\alpha_{\text {CAPM }}$ represent CAPM alpha, $\mathrm{R}_{\mathrm{e}}$ represent excess return, $\mathrm{R}_{\mathrm{mr}}$ represent market return, $R_{f}$ represents risk-free rate, and $\beta$ represent factor loading of market factor.

$$
\alpha_{\mathrm{FF}}=\mathrm{R}_{\mathrm{e}}-\beta_{1}\left(\mathrm{R}_{\mathrm{mr}}-\mathrm{R}_{\mathrm{f}}\right)-\beta_{2} \mathrm{SMB}-\beta_{3} \mathrm{HML}
$$

where $\alpha_{\mathrm{FF}}$ represent Fama-French alpha, SMB represent size factor, HML represents value factor and $\beta_{1}, \beta_{2}, \beta_{3}$ represents factor loadings.

\section{RESULTS}

\section{Profitability of momentum strategies}

The empirical analysis of this study starts with inspecting the performance of cross-sectional and time-series momentum strategies in the Indian stock market. In table 1, we have reported unconditional returns, risk-adjusted returns and Sharpe ratio of various momentum investment strategies. Panel A of table 1 reports the performances of various cross-sectional momentum strategies. Cross-sectional momentum strategies generate significant profits in the Indian market. These findings are consistent with the results of past studies on In- 
dian stock market. We find that raw returns of various cross-sectional strategies are significant in all cases, but risk-adjusted returns are not significant for longer time periods (9,12 months). Cross-sectional momentum delivers best results when we hold portfolios for one month. We find that performance of these strategies dramatically fall when we hold portfolios for longer time period signalling that these strategies reverse in the long run. Panel B of the same table represents performances of time-series momentum strategies. These strategies also generate significant returns in the Indian market. Even after adjusting the market and Fama-French factors, these returns remain significant. Similar to the findings of relative momentum, absolute momentum also delivers the best return when we hold portfolios for one month. We witness that absolute momentum strategies perform better than time momentum strategies. As one can see from the table in all holding periods, whether for raw returns or for risk-adjusted returns time series momentum strategies has generated excess returns than cross-sectional momentum strategies. This gap between the performances of time series and cross momentum strategies increases when we hold portfolios for longer period for example when we held portfolios for 12 months, time-series momentum generates a return of $1.764 \%$ per month. In contrast, cross-sectional momentum generates a return of $1.038 \%$ per month. Absolute momentum strategies also perform better than relative momentum strategies in terms of risk-reward ratio.

Table 1. Profitability of Cross-Sectional and Time-series momentum strategies

\begin{tabular}{|c|c|c|c|c|c|}
\hline \hline \multicolumn{7}{|c|}{ Panel A: Cross-Sectional Momentum } \\
\hline \hline K= & $\mathbf{1}$ & $\mathbf{3}$ & $\mathbf{6}$ & $\mathbf{9}$ & 12 \\
\hline \hline Raw Returns & $\begin{array}{c}1.954 \% \\
(4.475)\end{array}$ & $\begin{array}{c}1.735 \% \\
(3.631)\end{array}$ & $\begin{array}{c}1.367 \% \\
(2.982)\end{array}$ & $\begin{array}{c}1.135 \% \\
(2.648)\end{array}$ & $\begin{array}{c}1.038 \% \\
(2.200)\end{array}$ \\
\hline CAPM $\alpha$ & $\begin{array}{c}1.518 \% \\
(3.611)\end{array}$ & $\begin{array}{c}1.276 \% \\
(2.750)\end{array}$ & $\begin{array}{c}0.930 \% \\
(2.011)\end{array}$ & $\begin{array}{c}0.678 \% \\
(1.501)\end{array}$ & $\begin{array}{c}0.578 \% \\
(1.206)\end{array}$ \\
\hline Fama-French $\alpha$ & $1.661 \%$ & $1.427 \%$ & $1.087 \%$ & $0.854 \%$ & $0.782 \%$ \\
\hline Sharpe Ratio & $(4.028)$ & $(3.085)$ & $(2.315)$ & $(1.895)$ & $(1.655)$ \\
\hline \hline
\end{tabular}


Table 1. Profitability...

\begin{tabular}{|l|c|c|c|c|c|}
\hline \hline \multicolumn{7}{|c|}{ K= } & $\mathbf{1}$ & $\mathbf{3}$ & $\mathbf{6}$ & $\mathbf{9}$ & 12 \\
\hline \hline Raw Returns & $\begin{array}{c}2.326 \% \\
(4.822)\end{array}$ & $\begin{array}{c}1.876 \% \\
(3.908)\end{array}$ & $\begin{array}{c}1.672 \% \\
(3.626)\end{array}$ & $\begin{array}{c}1.392 \% \\
(3.332)\end{array}$ & $\begin{array}{c}1.764 \% \\
(3.598)\end{array}$ \\
\hline CAPM $\alpha$ & $\begin{array}{c}1.934 \% \\
(3.995)\end{array}$ & $\begin{array}{c}1.415 \% \\
(2.962)\end{array}$ & $\begin{array}{c}1.255 \% \\
(2.660)\end{array}$ & $\begin{array}{c}0.909 \% \\
(2.175)\end{array}$ & $\begin{array}{c}1.354 \% \\
(2.693)\end{array}$ \\
\hline Fama-French $\alpha$ & $2.149 \%$ & $1.616 \%$ & $1.489 \%$ & $1.135 \%$ & $1.637 \%$ \\
\hline Sharpe Ratio & $(4.616)$ & $(3.473)$ & $(3.206)$ & $(2.813)$ & $(3.490)$ \\
\hline \hline
\end{tabular}

The table 1 represents raw returns, risk-adjusted returns and risk-reward ratios of various cross-sectional and time-series momentum strategies. We rank the stocks on the basis of their past 12 months returns ( $\mathrm{t}-12$ to $\mathrm{t}-2$ ) and hold these for 1,3,6,9,12 months respectively. $\mathrm{K}$ represents holding period. Risk-adjusted returns are calculated using Capital Asset Pricing Model and Fama-French three-factor model. In parenthesis Newey-West robust $t$ statics $^{5}$ (with a lag of 6) are reported. Sharpe ratios are reported in annualized terms.

S o u r c e : authors' own calculations using R Software.

To examine whether time-series momentum consistently performs better than cross-sectional momentum, we further divide the sample period of the study into three subsamples: Jan 2002 to Dec 2007, Jan 2008 to Dec 2009 and Jan 2010 to Oct $2019^{6}$. The results of this subsample period analysis are presented in table 2 . We find that absolute momentum strategies perform better than relative momentum in each subsample period. These results are similar to the findings in table 1 . These findings prove that ability of time-series momentum to generate better return than cross-sectional momentum is not limited to specific time period only. Time series perform better cross-sectional momentum in every subsample period. Further, time-series momentum performs bet-

${ }^{5}$ We have used Newey-West $t$ statics because financial return series are not normally distributed. If a series is not normally distributed, we cannot use t test. Therefore, following the recommendations of Bali et al. (2016) we have used Newey-West $t$ statics.

${ }^{6}$ We have selected these three sample periods due to the fact that period from 2002 to 2007 represents boom period, the period from 2008 to 2009 represents depression period and the period from 2010 to 2019 represents recovery phase. 
ter in the first and last sample period. In comparison, cross-sectional momentum generated significant returns only in first subsample period.

Table 2. Performance of momentum strategies across different subsample periods

\begin{tabular}{|c|c|c|c|c|c|c|}
\hline \hline \multirow{2}{*}{ Time Period } & \multicolumn{2}{|c|}{ Cross-Sectional Momentum } & \multicolumn{3}{c|}{ Time Series Momentum } \\
\cline { 2 - 7 } & Raw Return & CAPM & FF3 & Raw Return & CAPM & FF3 \\
\hline \hline \multirow{2}{*}{$2002-2007$} & $\begin{array}{c}2.058 \% \\
(4.298)\end{array}$ & $\begin{array}{c}1.852 \% \\
(2.492)\end{array}$ & $\begin{array}{c}2.164 \% \\
(3.724)\end{array}$ & $\begin{array}{c}2.650 \% \\
(4.602)\end{array}$ & $\begin{array}{c}2.715 \% \\
(2.996)\end{array}$ & $\begin{array}{c}3.372 \% \\
(3.073)\end{array}$ \\
\hline $2008-2009$ & $-1.326 \%$ & $-1.987 \%$ & $-1.220 \%$ & $-0.764 \%$ & $-1.470 \%$ & $-0.907 \%$ \\
& $(-1.066)$ & $(-1.407)$ & $(-1.886)$ & $(-1.077)$ & $(-1.767)$ & $(-0.848)$ \\
\hline $2010-2019$ & $\begin{array}{c}1.249 \% \\
(1.650)\end{array}$ & $\begin{array}{c}0.679 \% \\
(1.049)\end{array}$ & $\begin{array}{c}0.558 \% \\
(0.713)\end{array}$ & $\begin{array}{c}2.091 \% \\
(2.872)\end{array}$ & $\begin{array}{c}1.541 \% \\
(2.273)\end{array}$ & $\begin{array}{c}1.417 \% \\
(1.689)\end{array}$ \\
\hline \hline
\end{tabular}

We sort the stocks on the basis of their previous 12 months ( $\mathrm{t}-12$ to $\mathrm{t}-2$ ) returns and hold these stocks for 12 months. Raw returns represent unconditional returns. CAPM and FF3 returns are calculated by regressing cross-sectional and time-series momentum returns with market return and Fama-French factors. Returns are reported in percentage terms. In brackets, Newey west t statistics are reported.

S o u r c e : authors' own calculations using R Software.

\section{Cross Alpha comparison}

To compare the performances of cross-sectional and time-series momentum strategies, we follow the methodology suggested by Moskowitz et al. (2012) and Goyal and Jegadeesh (2018). First, we regress the relative momentum profits against absolute momentum profits and find that alphas (intercept) are negative and insignificant. Then we regress absolute momentum profits against relative momentum profits and find significant positive alphas. Therefore, we can conclude that absolute momentum fully captures relative momentum, but relative momentum cannot fully explain absolute momentum.

Table 3 represents the intercepts when we regress relative momentum profits against absolute momentum profits and absolute momentum profits against relative momentum profits. We report these results for all five holding periods. When we regress time-series momentum profits against cross-sectional momentum profits, we find three of five holding periods generated significant and positive alphas. As one can see from the table that when we hold portfolios for 1,3 and 12 months at that time, alphas are significant and positive. On the 
other hand, when cross-sectional momentum profits are regressands and timeseries momentum profits are regressors, the alphas are negative and insignificant. For instance, when we hold portfolio for 12 months, the alpha is $-0.284 \%$. These findings are similar to the findings of Moskowitz et al. (2012) and Goyal and Jegadeesh (2018). Therefore, one can say that absolute momentum fully captures relative momentum, but relative momentum cannot fully explain absolute momentum.

Table 3. Cross-alphas of various cross-sectional and time-series momentum returns

\begin{tabular}{|c|c|c|}
\hline \multicolumn{2}{|c|}{$\begin{array}{c}\text { Independent Variable } \longrightarrow \text { Cross-Sectional } \\
\text { Dependent VariableCross-Sectional } \longrightarrow \text { Time-Series }\end{array}$} & \multirow[t]{2}{*}{$\begin{array}{l}\text { Time-Series } \\
\text { Cross-Sectional }\end{array}$} \\
\hline Holding Period & & \\
\hline 1 & $\begin{array}{l}0.476 \% \\
(2.037)\end{array}$ & $\begin{array}{l}0.083 \% \\
(0.347)\end{array}$ \\
\hline 3 & $\begin{array}{l}0.346 \% \\
(1.360)\end{array}$ & $\begin{array}{l}0.138 \% \\
(0.452)\end{array}$ \\
\hline 6 & $\begin{array}{l}0.368 \% \\
(1.362)\end{array}$ & $\begin{array}{l}0.000 \% \\
(-0.003)\end{array}$ \\
\hline 9 & $\begin{array}{l}0.458 \% \\
(1.978)\end{array}$ & $\begin{array}{l}0.039 \% \\
(0.174)\end{array}$ \\
\hline 12 & $\begin{array}{c}0.729 \% \\
(2.545)\end{array}$ & $\begin{array}{l}-0.284 \% \\
(-0.934)\end{array}$ \\
\hline
\end{tabular}

This table presents alphas of cross-sectional momentum returns regressed with time-series momentum returns and alphas of time-series momentum returns regressed with cross-sectional momentum returns. Alphas are reported in percentage terms. In brackets, we have reported Newey-West robust t statistics (with a lag of 6).

S o u r c e : authors' own calculations using R Software.

The results from the above table prove that time-series momentum strategies perform better than cross-sectional momentum strategies. Now the question arises why time-series momentum strategies perform better than crosssectional momentum strategies. For this, we need to find out the sources of difference between the performances of these two strategies. 


\section{Sources of difference between cross-sectional and time-series momentum returns}

If we see formulation structure of cross-sectional and time-series momentum strategies, we can say that cross-sectional momentum strategies are "zero net investment long/short strategies" whereas in time-series momentum strategies investors take long or short positions on the basis of number of stocks generated positive and negative returns. Investors would have a net long position for a particular month if more than half of the stocks have generated positive return in the past and a net short position if most of the stocks have generated negative returns in the past. Therefore, the formulation structure of the timeseries momentum strategies automatically adds net long (or net short) position component in these strategies. To compare the absolute and relative momentum, we have taken into consideration extra risk premium that absolute momentum strategies gain relative to relative momentum strategies due to this net long position. We will add this additional risk premium component in crosssectional momentum by investing the net long position in any random portfolio. The rupee amount invested in this portfolio will change through time. For example, time-series momentum strategy will invest ₹ 1.10 and ₹0.90 in the long and short portfolio, respectively if 55 stocks generated positive returns in the past, and 45 stocks generated negative returns. In this case the net long position of ₹ 0.20 will be invested in a random portfolio. Goyal and Jegadeesh (2018) refer to this investment as "time-varying investment" in the market. We will add this "time-varying investment" in the cross-sectional momentum and will term this sum as $\mathrm{CS}_{\text {TVM. }}$. If $\mathrm{CS}_{\text {TVM }}$ performs same as time-series momentum, we can say that time-series momentum is not completely new phenomena, net long position is the only reason of superior performance of time-series momentum over cross-sectional momentum.

In table 4, we compare the performances of time-series momentum (TS), cross-sectional momentum (CS) and the sum of cross-sectional momentum and "time-varying investment" ( $\mathrm{CS}_{\mathrm{TVM}}$ ). We also report the difference between TS and CS and TS and $\mathrm{CS}_{\mathrm{TVM}}$. We report these results when we hold stocks throughout 12 months because when we hold the portfolio for longer periods, the difference between the performances of relative momentum and absolute momentum increases. The net long position for this strategy is ₹0.36 (on an average we invested ₹1.18 on the long side and ₹ 0.82 on the short side). When we com- 
pare the difference between the absolute momentum and relative momentum, the difference is large and statically significant. However, when we add "timevarying investment" in the cross-sectional momentum and compare this sum with time-series momentum, we find that difference is small and statically insignificant. From these findings, we can conclude that net long investment is the main reason behind the significant performance of time series momentum over time-series momentum.

Table 4. Comparison of cross-sectional and time-series momentum

\begin{tabular}{|c|c|c|c|c|c|c|}
\hline \hline TS & CS & CS $_{\text {TVM }}$ & TS-CS & TS-CS $_{\text {TVM }}$ & ₹Long & ₹Short \\
\hline \hline $\begin{array}{c}1.764 \% \\
(3.598)\end{array}$ & $\begin{array}{c}1.038 \% \\
(2.200)\end{array}$ & $\begin{array}{c}1.461 \% \\
(2.914)\end{array}$ & $\begin{array}{c}0.725 \% \\
(2.264)\end{array}$ & $\begin{array}{c}0.301 \% \\
(0.729)\end{array}$ & ₹ 1.18 & ₹ 0.82 \\
\hline \hline
\end{tabular}

S o u r c e : authors' own calculations using R Software.

\section{Discussions}

The findings of the present study are consistent with the existing momentum investing literature. The present study reports that both absolute and relative momentum strategies generate large and significant momentum payoffs in Indian stock market. Both strategies perform superior returns in the short window (12 months' formation and one month holding period) than the long window (12 months' formation and 12 months holding period). Consistent with the findings of Lim et al. (2018), absolute momentum strategies generate superior returns than relative momentum strategies (in all cases). Absolute momentum payoffs remain significant in longer time frames signalling that unlike relative momentum strategies, these strategies do not reverse in the long run. Further, the study regresses the cross-sectional momentum payoffs on time-series momentum payoffs and time-series momentum payoffs on cross-sectional payoffs. We document that absolute momentum strategies can capture relative momentum payoffs. However, relative momentum payoffs cannot capture absolute momentum payoffs. These findings are in accordance with the results of Moskowitz et al. (2012). Supporting the results of Goyal and Jegadeesh (2018), the present study also finds that "time-varying net long position" is the main factor behind the superior performance of time-series momentum strategies. From the practitioner's point of view, the findings of the study will assist active 
investors in consistently generating superior returns. Future research studies can focus on potential explanations of the time-series momentum effect.

\section{CONCLUSION}

Although there are a number of research studies available on momentum, most of them most focus on cross-sectional momentum, whereas absolute momentum is a comparatively new phenomenon. In this study, we test the performances of cross-sectional and time-series momentum strategies in the Indian stock market. Both cross-sectional and time-series momentum strategies generate significant profits over the sample period from 2002 to 2019. Clearly, time-series momentum strategies perform better than cross-sectional momentum. Time-series momentum strategies also perform better when we hold portfolios for longer time whereas returns from cross-sectional momentum strategies decline in long time periods. Though both time series and cross-sectional momentum strategies select stocks on the basis of their past performance in timeseries momentum strategies we select stocks on the basis of their own past performance whereas in cross-sectional momentum we select stocks on the basis of their relative performance. When we compare performances of time-series momentum strategies with cross-sectional momentum strategies, we find that due to more investments in long positions, time-series momentum strategies perform better than cross-sectional momentum. Our findings contribute to the literature on financial anomalies by giving the initial evidence of significant timeseries momentum effect in Indian stock market. Given the fact that Indian stock market is the second most preferred destination (among emerging countries) for global fund managers, the findings of the study will help local and global fund managers in the formulation of more profitable equity strategies.

\section{REFERENCES}

Asness, C.S., Moskowitz, T.J., \& Pedersen, L.H. (2013). Value and Momentum Everywhere. The Journal of Finance, 68(3), 929-985. http://dx.doi.org/10.1111/jofi.12021.

Bali, T.G., Engle, R.F., \& Murray, S. (2016). Empirical Asset Pricing: The Cross Section of Stock Returns. Hoboken: John Wiley \& Sons.

Beracha, E., \& Skiba, H. (2011). Momentum in Residential Real Estate. The Journal of Real Estate Finance and Economics, 43(3), 299-320. http://dx.doi.org/10.1007/s11146009-9210-2. 
Bird, R., Gao, X., \& Yeung, D. (2017). Time-series and cross-sectional momentum strategies under alternative implementation strategies. Australian Journal of Management, 42(2), 230-251. https://doi.org/10.1177/0312896215619965.

Chan, L.K.C., Jegadeesh, N., \& Lakonishok, J. (1996). Momentum Strategies. The Journal of Finance, 51(5), 1681-1713. http://dx.doi.org/10.1111/j.1540-6261.1996.tb05222.x.

Conrad, J., \& Kaul, G. (1998). An Anatomy of Trading Strategies. The Review of Financial Studies, 11(3), 489-519. http://dx.doi.org/10.1093/rfs/11.3.489.

Derwall, J., Huij, J., Brounen, D., \& Marquering, W. (2009). REIT Momentum and the Performance of Real Estate Mutual Funds. Financial Analysts Journal, 65(5), 24-34. http://dx.doi.org/10.2469/faj.v65.n5.4.

$\mathrm{Du}, \mathrm{D}$. (2008). The 52-week high and momentum investing in international stock indexes. The Quarterly Review of Economics and Finance, 48(1), 61-77. http://dx.doi. org/10.1016/j.qref.2007.02.001.

Fama, E.F., \& French, K.R. (1992). The Cross-Section of Expected Stock Returns. The Journal of Finance, 47(2), 427-465. http://dx.doi.org/10.1111/j.1540-6261.1992. tb04398.x.

Fuertes, A.-M., Miffre, J., \& Fernandez-Perez, A. (2015). Commodity Strategies Based on Momentum, Term Structure, and Idiosyncratic Volatility. Journal of Futures Markets, 35(3), 274-297. http://dx.doi.org/10.1002/fut.21656.

Garg, A.K., \& Varshney, P. (2015). Momentum Effect in Indian Stock Market: A Sectoral Study. Global Business Review, 16(3), 494-510. http://dx.doi.org/10.1177 /0972150915569940.

Goyal, A., \& Jegadeesh, N. (2018). Cross-Sectional and Time-Series Tests of Return Predictability: What Is the Difference? The Review of Financial Studies, 31(5), 1784-1824. http://dx.doi.org/10.1093/rfs/hhx131.

Griffin, J.M., Ji, X., \& Martin, J.S. (2003). Momentum Investing and Business Cycle Risk: Evidence from Pole to Pole. The Journal of Finance, 58(6), 2515-2547. http://dx.doi. org/10.1046/j.1540-6261.2003.00614.x.

Grobys, K., \& Sapkota, N. (2019). Cryptocurrencies and momentum. Economics Letters, 180, 6-10. http://dx.doi.org/10.1016/j.econlet.2019.03.028.

Jegadeesh, N., \& Titman, S. (1993). Returns to Buying Winners and Selling Losers: Implications for Stock Market Efficiency. The Journal of Finance, 48(1), 65-91. http:// dx.doi.org/10.1111/j.1540-6261.1993.tb04702.x.

Jegadeesh, N., \& Titman, S. (2001). Profitability of Momentum Strategies: An Evaluation of Alternative Explanations. The Journal of Finance, 56(2), 699-720. http://dx.doi. org/10.1111/0022-1082.00342.

Jostova, G., Nikolova, S., Philipov, A., \& Stahel, C. W. (2013). Momentum in Corporate Bond Returns. The Review of Financial Studies, 26(7), 1649-1693. http://dx.doi. org/10.1093/rfs/hht022.

Lim, B.Y., Wang, J.G., \& Yao, Y. (2018). Time-series momentum in nearly 100 years of stock returns. Journal of Banking \& Finance, 97, 283-296. http://dx.doi.org/10.1016/j. jbankfin.2018.10.010. 
Lin, Q. (2019). Residual momentum and the cross-section of stock returns: Chinese evidence. Finance Research Letters, 29, 206-215. http://dx.doi.org/10.1016/j. frl.2018.07.009.

Maheshwari, S., \& Dhankar, R.S. (2017). Momentum anomaly: Evidence from the Indian stock market. Journal of Advances in Management Research, 14(1), 3-22. http:// dx.doi.org/10.1108/JAMR-11-2015-0081.

Menkhoff, L., Sarno, L., Schmeling, M., \& Schrimpf, A. (2012). Currency momentum strategies. Journal of Financial Economics, 106(3), 660-684. http://dx.doi.org/10.1016/j. jfineco.2012.06.009.

Mohapatra, S., \& Misra, A.K. (2020). Momentum returns: A portfolio-based empirical study to establish evidence, factors and profitability in Indian stock market. IIMB Management Review, 32(1), 75-84. http://dx.doi.org/10.1016/j.iimb.2019.07.007.

Moskowitz, T.J., Ooi, Y.H., \& Pedersen, L.H. (2012). Time series momentum. Journal of Financial Economics, 104(2), 228-250. http://dx.doi.org/10.1016/j.jfineco.2011.11.003.

Okunev, J., \& White, D. (2003). Do Momentum-Based Strategies Still Work in Foreign Currency Markets? Journal of Financial and Quantitative Analysis, 38(2), 425-447. http://dx.doi.org/10.2307/4126758.

Rouwenhorst, K.G. (1998). International Momentum Strategies. The Journal of Finance, 53(1), 267-284. http://dx.doi.org/10.1111/0022-1082.95722.

Sehgal, S., \& Balakrishnan, I. (2002). Contrarian and Momentum Strategies in the Indian CapitalMarket.Vikalpa,27(1),13-20.http://dx.doi.org/10.1177/0256090920020103.

Sehgal, S., \& Jain, K. (2015). Dissecting sources of price momentum: Evidence from India. International Journal of Emerging Markets, 10(4), 801-819. http://dx.doi. org/10.1108/IJoEM-04-2014-0046. 